\title{
GENERASI MUDA MEMBANGUN DESA WISATA (STUDI : DESA WISATA BRAYUT, SLEMAN YOGYAKARTA)
}

\author{
Derry Ahmad Rizal \\ Email:bloer@rocketmail.com
}

\begin{abstract}
The village becomes a comfortable place to live, because it still looks beautiful and fresh air. The urban community who originally came from the village even flocked to leave their village to earn money. Long life in the city, it causes the boredom for the urban community and they miss the village that was ever occupied. Tourism village becomes one of the urban communities to release the longing for the village that once lived. Tourism village is intentionally designed, made a tourismplace with the concept of rural life in general. In the process of rural tourism development, it must all elements in the village to be built, including the young generation. Today, many young people do not care about their respective villages, whereas the young generation becomes the hope to be the next local wisdom. How is the role of the young generation in building a tourism village? The purposes are to find out how far the role of the young generation in building a tourism village, with various problems experienced by the young generation. This type of research used descriptive qualitative method, the approach that researcher used in this research was phenomenological approach. Researcher in this research tried to understand how the role of the young generation in developing tourism village and various problems faced by the young generation. How is the process towards becoming a tourism village?
\end{abstract}

Keywords: Generation, Young, Building, Tourism 


\section{A. Pendahuluan}

Daerah Istimewa Yogyakarta yang memang dikenal oleh khalyak umum mengenai budaya atau adat yang masih kuat karena sistem kerajaan yang hingga sampai hari ini masih berjalan yaitu Kraton. Akan tetapi bukan hanya di wilayah Kraton saja budaya yang bertahan, untuk wilayah pinggiran desa-desa yang jauh dari pusat Kraton pun masih mempertahankan budayanya. Beberapa desa-desa yang mempertahankan budaya dengan cara menjadikan desa tersebut desa wisata dengan tujuan; mempertahankan budaya yang ada agar tidak luntur, mengenalkan pada khalayak umum mengenai budaya tersebut, untuk peningkatan ekonomi desa juga karena mendapatkan pemasukkan.

\section{Implementasi}

dalam pengembangan ekowisata di Provinsi Yogyakarta diwujudkan dalam bentuk Desa Wisata yang tersebar hampir di beberapa wilayah kabupaten dankota diantaranya Kabupaten Bantul, Kabupaten Sleman, Kabupaten Kulon Progo dan Kabupaten Gunung Kidul. Ada beberapa eko wisata yang sudah relatif maju dan berkembang, tetapi sebagian besar masih membutuhkan dorongan dan perhatian ekstra dari Pemerintah karena memang diharapkan masyarakat menjadi pengelola sekaligus penangung jawab pelaksanaan Desa Wisata tersebut. ${ }^{1}$

1 Joko Tri Haryanto, “ Implementasi Nilai-Nilai Budaya, Sosial, dan Lingkungan dalam Pengembangan Desa Wisata di Provinsi
Desa wisata merupakan salah satu bentuk penerapan pembangunan pariwisata berbasis masyarakat dan berkelanjutan. Melalui pengembangan desa wisata diharapkan terjadi pemerataan yang sesuai dengan konsep pembangunan pariwisata yang berkesinambungan. Di samping itu, keberadaan desa wisata menjadikan produk wisata lebih bernilai budaya pedesaan sehingga pengembangan desa wisata bernilai budaya tanpa merusaknya. ${ }^{2}$ Ada beberapa tipe mengenai desa wisata menurut pengamatan penulis, pertama, desa wisata jenis pertanian lebih menekankan pada aspek pertanian sekaligus mengajak wisatawan yang datang untuk bertani dan memanen hasil pertanian. Menjadi edukasi pertanian sendiri kepada wisatawan agar lebih menghargai jerih payah petani. Kedua, desa wisata budaya, tipe desa wisata ini memperlihatkan kegiatan-kegiatan budaya yang memang menjadi ciri khas desa tersebut, semisal jathilan (tarian daerah). Ketiga, desa wisata berbasis outbond, desa jenis ini lebih kepada edukasi-edukasi permainan yang dilakukan di desa-desa, seperti susur sungai, berjalan dengan seutas tali di atas kolam. Masih banyak ragam

Yogyakarta," Kawistara, Vol. 3, No. 1, (April 2013), 1-11

2 Made Heny Urmila Dewi. "Pengembangan Desa Wisata Berbasis Partisipasi Masyarakat Lokal Di Desa Wisata Jatiluwih Kabupaten Tabanan, Bali." Kawistara, Vol. 3, No. 2, (Agustus 2013), 129-139 
dari desa wisata yang ada di Daerah Istimewa Yogyakarta.

Wisatawan yang datang ke desa wisataitu akan dapat menikmati alam perdesaanyang masih bersih dan merasakan hidupdisuasana desa dengan sejumlah adatistiadatnya. Wisatawan tinggal bersama penduduk, tidur dikamar yang sederhana tapi bersih dan sehat, makanan tradisional merupakan hidangan utama yang hendakdisajikan selama di desa wisata, wisatawan merasakan adanya kepuasankarena adanya penyambutan, danpelayanan dari penduduk desa tersebut. ${ }^{3}$

Dalam proses pembangunan desa wisata haruslah semua elemen yang ada di desa tersebut membangun, tanpa terkecuali genereasi muda pun masuk dalam elemen tersebut. Melihat dewasa ini, generasi muda banyak yang tidak memperdulikan desanya masing-masing. Padahal generasi muda menjadi harapan untuk menjadi kearifan lokal selanjutnya.

Pembangunan merupakan suatu proses perubahan sosial dengan harapan meningkatnya partisipasi yangluas dari masyarakat untuk kemajuan sosial dan material (termasuk di dalamnya bertambah besarnya keadilan, kebebeasan dan kualitas lainnya yang dihargai) melalui control yang lebih besar dengan tujuan meningkatkan pendapatan

3 Dewi Winarni Susyanti, "Potensi Desa Melalui Pariwisata Pedesaan,”Epigram, Vol. 11 No.1 (April 2014), 65-70 masyarakat yang bersumber dalam lingkungannya. ${ }^{4}$

Berdasarkan hal ini maka generasi muda yang menjadi harapan bangsa memulai melakukan perbaikan kesejahteraan mulai dari desa dimana meraka tinggal walaupun di beberapa wilayah lainnya generasi muda malah bergantung pada generasi tua. Padahal generasi mudalah yang seharusnya meneruskan dan memberikan inovasi guna peningkatan kesejahteraan. Tujuan dari penelitian ini untuk mengetahui sejauh mana peranan generasi muda dalam membangun desa wisata, dengan berbagai problema yang teralami generasi muda.

\section{B. Metode Kajian}

Jenis penelitian ini menggunakan metode kualitatif deskriptif, pendekatan yang peneliti gunakan dalam penelitian ini adalah pendekatan fenomenologis.Pendekatan yang peulis gunakan dalam penelitian ini adalah pendekatan fenomenologis. Penulis dalam penelitian ini berusaha memahami peristiwa dan kaitankaitannya terhadap orang-orang biasa dalam situasi tertentu. ${ }^{5}$ Sedangkan istilah fenomenologi asal katanya adalah fenomena yang dalam bahasa Yunani yakni phainomena (yang berakar kata phanein yang berarti menampak)

4 Nasution, " Komunikasi Pembangunan: pengelanan Teori dan Penerapan." Edisi revisi,(Jakarta: Rajawali Pers, 2002)

5 Lexy J. Moloeng, Metodologi Penelitian Kualitatif, (Bandung: PT Remaja Rosdakarya, 2010), 9. 
sering digunakan untuk merujuk ke semua obyek yang masih dianggap eksternal secara paradigmatik harus disebut obyektif. Fenomena adalah gejala dalam situasi alamiah yang kompleks, yang hanya mungkin menjadi bagian dari alam kesadaran manusia sekomprehensif apapun manakala telah direduksi dalam suatu barometer yang terdefinisikan sebagai fakta, dan yang demikian terwujud sebagai suatu realitas. ${ }^{6}$

Peneliti dalam penelitian ini berusaha memahami bagaimana peranan dari generasi muda dalam membangun desa wisata dan berbagai problema yang dihadapi generasi muda. Bagaimana proses menuju menjadi desa wisata?

\section{Teori}

Empowerment atau yang biasa disebut pemberdayaan memang sudah lama terngiang di khalayak umum khususnya pada tahun 1990an. Paradigma pemberdayaan ialah pembangunan berpusat pada rakyat merupakan proses pembangunan yang mendorong prakarsa masyarakat berakar dari bawah. ${ }^{7}$ Dalam menciptakan pengembangan yang kondusif menurut Budiman

6 SoetandyaWignojosoebroto, "Fenomena Cq Realitas Sosial Sebagai Obyek Kajian Ilmu (Sains) Sosial”, dalam Burhan Bungin (editor), Metodologi Kualitatif Aktualisasi Metodologi Ke Arah Ragam Varian Kontemporer (Jakarta: PT Raja Grafindo, 2001), 17.

7 Dr. Alfitri, M.Si, "Community Development; Teori dan Aplikasi,” (Yogyakarta : Pustaka Pelajar, 2011), 21 harus diciptakan kondisi-kondisi yang membuat manusia bisa mengembangkan kreatifitasnya. Bagaimanapun juga pembangunan pada akhirnya harus ditujukan pada pembangunan manusia. Manusia yang dibangun adalah manusia yang kreatif. Untuk bisa kreatif, manusia tersebut harus merasa bahagia, merasa aman dan bebas dari rasa takut. Hanya manusia seperti inilah yang bisa menyelenggarakan pembangunan dan memecahkan masalah yang dijumpainya. ${ }^{8}$

Berkembang dari teori pemberdayaan, pengembangan masyarakat atau community development ialah salah satu modelnya. Community development adalah proses yang dilakukan atas usaha masyarakat sendiri yang diintegrasikan dengan otonomi daerah guna memperbaiki kondisi sosial ekonomi dan kultural komunitas, mengintegrasikan komuniats ke dalam kehidupan nasional. ${ }^{9}$ Dalam Al-Quran pun dibahas mengenai pengembangan masyarakat dalam Surat Ar-Ra'du : 11 dinyatakan bahwa "Allah tidak akan mengubah suatu kaum sehingga mereka mengubah keadaan yang ada pada diri meraka sendiri." 10

8 Arief Budiman, "Teori Pembangunan Dunia Ketiga.” (Jakarta: Gramedia Pustaka Utama,1996), 14.

9 Dr. Alfitri, M.Si, "Community Development; Teori dan Aplikasi," (Yogyakarta : Pustaka Pelajar, 2011), 32

10 QS.Ar-Ra'du : 11 
Model dari community development banyak menggunakan pola top down ialah peraturan atau kebijakan yang dilakukan oleh pemerintah untuk masyarakatnya. Kekurangan dari pola top down terkadang melihat cover saja tanpa meng-assesment lebih dalam sehingga kurang tepat dalam pemberian kebijakan.

\section{Hasil dan Pembahasan}

Menilik sejarah Desa Brayut sebagaimana pemaparan dalam acara seminar nasioanal Jurusan Pengembangan Masyarakat Islam UIN Sunan Kalijagapada 12 November2015, A.Sudarmadi selakuketua pengelola desa wisata Brayut menceritakan mengenai asal-usul keberadaan desa wisata Brayut. Awal mula berdirinya Desa wisata Brayut ialah bermula dari salah satu pemuda yang mengajar di sebuah lembaga pendidikan bahasa asing (PURI) Yogyakarta pada tahun 1999, namanya Bapak Budi Utomo dan salah satu mata kuliah yang diajarkan adalahbahasaIndonesiasehinggabeliau mencoba mengajak mahasiswanya untuk mengunjungi Desa Brayut yang pada mulanya terhampar pertanian yangluas dan mahasiswanya pun diajak berinteraksi bersama warga sekitar dengan mempraktekkan beberapa kegiatan tradisional di desa itu dan belajar bercocok tanam layaknnya petani di Desa Brayut. Respon yang didapat dari mahasiswa cukupbaik sehingga setiap mengampu mata kuliah tersebut Bapak Budi selalu mengajakmahasiswanya mengunjungi
Desa Brayut. Dan lama-kelamaan hal tersebut dianggap sebagai sebuah peluang sebagai alternatif wisata, awal mulanya diberi nama Yayasan AniAniyang sebagaimana dicanangkan menjadi desa wisata. ${ }^{11}$ Yayasan AniAni berjalan hingga terjadi peristiwa bom bali I, lalu vakum dan pada tahun 2004 mulai aktif kembali sekaligus diresmikannya desa wisata oleh Bpk A.Sudarmadi.

Dari proses menjadi desa wisata, seperti pemaparan diatas setiap elemen turun tangan dalam menangani tak terkecuali para pemudanya pun turut serta. Kesadaran yang masih kuat dari parapemudaDesaBrayutdandorongan semangat dari para sepuh termasuk Bapak Sudarmadi membuahkan hasil yang tidak sia-sia. Pada tahun 2012 Desa Brayut menjadi tuan rumah dari acara Ngayogjazz untuk kali pertama, lalu pada tahun 2014 kali keduanya Desa Brayut menjadi tuan rumah acara Ngayogjazz. ${ }^{12}$ Ngayogjazz sendiri adalah acara festival musik jazz tahunan di Daerah Istimewa Yogyakarta yang diselenggarakan oleh para seniman dan komunitas jazz lokal Yogyakarta dari sejak tahun 2007.

11 Notulen Seminar Nasional "Village Creative Tourism And Culture", acara seminar Jurusan Pengembangan Masyarakat Islam UIN Sunan Kalijaga Yogyakarta Sabtu, 12 Novermber 2011

12 Muhammad Najih Farihanto, "Dinamika Komunikasi Dalam Pembangunan Desa Wisata Brayut Kabupaten Sleman.,'Jurnal Penelitian Pers dan Komunikasi Pembangunan.,Vol. 19 No.3 (Februari 2016), 203-214 


\section{E. Kesimpulan}

Sebagaimana pemaparan diatas, yang awalnya perkenomian Desa Brayut bergantung kepada pertanian kini meningkat dengan adanya desa wisata. Pemberdayaan yang dilakukan sejumlah pemuda dalam melakukan pemberdayaan terhadap masyarakat desa, bukan berawal dari kebijakan pemerintah. Terbukti meng-assesment mendalam dari masyarakat, menggali apa yang menjadi kegiatan tradisional selama ini dan potensi alam apa yang bisa dikembangkan di Desa Brayut. Peran dan kesadaran dari elemen masyarakat desa memang diperlukan untuk pembangunan, terlebih peran pemuda yang memang mempunyai pemikiran lebih maju untuk samasama membangun bukan berarti menggurui.

Generasi muda yang turut membangun desa wisata Brayut bersama ketua desa wisata Brayut yaitu Bapak Sudarmadji. Walapun dalam penelitian sebelumnya yang dilakukan Muhammad Najih Farihanto menyebutkan bahwa terdapat sedikit miss communication antara golongan orang tua dan pemudanya dalam pelaksanaan Ngayogjazz tetapi Bapak Sudarmadji mengambil keputusan untuk terbaik untuk melanjutkan dan meng-iya-kan pelaksanaan acara tersebut.

Selain acara Ngayogjazz, kegiatan harian atau mingguan dikala mendapat kunjungan wisatawan untuk dilakukannya kegiatan-kegiatan desa seperti budaya (jathilan) atau edukasi lainnya yang terdapat di Desa Brayut pemuda turut serta dalam melaksanakannya. Generasi muda seperti ini yang menjadi harapan di setiap desa ataupun daerah, yang mempunyai kesadaran tinggi untuk membangun dan meningkatkan ekonomi dari desa tempat mereka tinggal. Diperlukan pengenalan ilmu mengenai menggali potensi alam yang dimiliki, agar desa tidak ditinggalkan penduduknya dan budaya hilang karena ditinggalkan penduduknya.

\section{Daftar Pustaka}

Al-Qur'an

QS.Ar-Ra'du : 11

Buku

Nasution, Komunikasi Pembangunan: pengelanan Teori dan Penerapan. Edisi revisi,(Jakarta: Rajawali Pers, 2002)

Soetandya

Wignojosoebroto, Fenomena $\mathrm{Cq}$ Realitas Sosial Sebagai Obyek Kajian Ilmu (Sains) Sosial, dalam Burhan Bungin (editor), Metodologi Kualitatif Aktualisasi Metodologi Ke Arah Ragam Varian Kontemporer (Jakarta: PT Raja Grafindo, 2001)

Alfitri, M.Si, Community Development; Teori dan Aplikasi, (Yogyakarta : Pustaka Pelajar, 2011) 
Lexy J. Moloeng, Metodologi Penelitian Kualitatif, (Bandung: PT Remaja Rosdakarya, 2010)

Budiman, Arief. "Teori Pembangunan Dunia Ketiga.” (Jakarta: Gramedia Pustaka Utama,1996)

Jurnal

Joko Tri Haryanto, "Implementasi Nilai-Nilai Budaya, Sosial, dan Lingkungan dalam Pengembangan Desa Wisata di Provinsi Yogyakarta," Kawistara, Vol. 3, No. 1, (April 2013)

Dewi Winarni Susyanti, "Potensi Desa Melalui Pariwisata Pedesaan,"
Epigram, Vol. 11 No.1 (April 2014)

Muhammad Najih Farihanto, "Dinamika Komunikasi Dalam Pembangunan Desa Wisata Brayut Kabupaten Sleman., "Jurnal Penelitian Pers dan Komunikasi Pembangunan., Vol. 19 No.3 (Februari 2016)

Notulen Seminar Nasional "Village Creative Tourism And Culture", acara seminar Jurusan Pengembangan Masyarakat Islam UIN Sunan Kalijaga Yogyakarta Sabtu, 12 Novermber 2011 